\title{
Modifications in Gamma-aminobutyric Acid type A Receptor Subunit Gene Expression During Macrophage Differentiation and Propofol Administration in THP-1 Cells
}

\author{
Tsukasa Kochiyama \\ Juntendo University School of Medicine \\ Izumi Kawagoe ( $\nabla$ ikawago@juntendo.ac.jp ) \\ Juntendo University School of Medicine \\ Ai Yamaguchi \\ Juntendo University School of Medicine \\ Masataka Fukuda \\ Juntendo University School of Medicine \\ Masakazu Hayashida \\ Juntendo University School of Medicine
}

\section{Research Article}

Keywords: GABAA receptor subunit, Macrophages, Monocytes, Propofol, THP-1 cell

Posted Date: October 11th, 2021

DOI: https://doi.org/10.21203/rs.3.rs-907961/v1

License: (c) (1) This work is licensed under a Creative Commons Attribution 4.0 International License.

Read Full License 


\section{Abstract}

Background: Gamma-aminobutyric acid type $A\left(G_{A B A}\right)$ receptors are thought to play a role in the functioning of the immune system. $\mathrm{GABA}_{A}$ receptors have 19 types of subunits, the components of which determine their physiological functions. However, the subunits that are expressed in immune cells during inflammation have not been fully investigated. Recent reports have shown that anesthetic agents may affect the gene expression of $\mathrm{GABA}_{\mathrm{A}}$ receptors subunits in immune cells. Therefore, we aimed to investigate the changes in $\mathrm{GABA}_{A}$ receptor subunit gene expression during macrophage differentiation and propofol administration in order to clarify the relationship between the expression of $G_{A B A}$ receptors and the immunomodulatory effect of propofol.

Methods: Human acute monocytic leukemia (THP-1) cells were differentiated into macrophage-like cells (M0 THP-1); subsequently, M0 THP-1 cells were differentiated into inflammatory M1 macrophage-like cells (M1 THP-1). Propofol was administered during the differentiation into M1 THP-1 cells. Using reverse transcriptase polymerase chain reaction, we examined which $\mathrm{GABA}_{\mathrm{A}}$ receptor subunit genes were expressed and whether there were changes in the gene expression during macrophage differentiation and propofol administration in THP-1 cells.

Results: The expression of the $\alpha 1, \alpha 4, \beta 1, \beta 2, \gamma 1$, and $\gamma 2$ subunits increased during differentiation into $\mathrm{M} 0$ THP-1 cells. The expression of the $\alpha 1, \alpha 4, \beta 1, \beta 2, \gamma 2$, and $\delta$ subunits decreased and that of the $\gamma 1$ subunit increased during differentiation into M1 THP-1 cells. The gene expression of the $a 1, a 4$, and $\beta 2$ subunits increased upon administering propofol during differentiation into M1 THP-1 cells.

Conclusions: The gene expression of $\mathrm{GABA}_{A}$ receptor subunits changed during macrophage differentiation in THP-1 cells. The expressions of a1 and a4 increased following propofol administration during the differentiation into M1 THP-1 cells, which may indicate that the GABA ${ }_{A}$ receptor is involved in the immunosuppressive effects of propofol. This study can help in the choice of anesthetic agents for proinflammatory conditions such as highly-invasive surgery.

\section{Background}

Gamma-aminobutyric acid type $A\left(G_{A B A}\right)$ receptors are ligand-gated anion channels that are activated when gamma-aminobutyric acid (GABA) binds to them. GABA is a major inhibitory neurotransmitter. The function of GABA has been well studied in the central nervous system; however, few studies are available on GABA expression related to physiological functions in other tissues. In particular, the expression of $G_{A B A_{A}}$ receptors and their functions in immune cells have not been fully investigated. GABA $A$ receptor expression has been confirmed in monocytes [1], human acute monocytic leukemia cell lines (THP-1 cells), macrophages [2], and T-cells [3, 4]. Monocytes and macrophages produce GABA, which inhibits the production of inflammatory cytokines [5-7]. Hence, it has been hypothesized that the GABAergic signaling system is also present among immune cells, regulating cellular functions, such as cell proliferation, cytokine production, phagocytosis, and chemotaxis $[2,5,7]$. 
The $\mathrm{GABA}_{A}$ receptor is a pentamer consisting of three different subunits. There are 19 different types of $\mathrm{GABA}_{A}$ receptor subunits $(\alpha 1-6, \beta 1-3, \gamma 1-3, \delta, \varepsilon, \pi, \theta$, and $\rho 1-3) . \mathrm{GABA}_{A}$ receptors are mainly composed of $2 a, 2 \beta$, and $1 \gamma$ or $1 \delta$ [8]. Since the difference in composition determines the specific function and pharmacological properties of the channel, the identification of subunit expression in cells is crucial. The hypnotic effect of anesthetics is produced by the $\mathrm{GABA}_{A}$ receptors [9]. Propofol, a predominant hypnotic agent in the anesthetic field, is known to act on immune cells, resulting in immunomodulatory effects.[10, $11]$.

Macrophages are immune cells that are present in various tissues throughout the body. Monocytes differentiate into macrophages when they migrate to tissues throughout the body. During inflammatory processes, macrophages differentiate into M1 macrophages, which act as inflammatory cells, and M2 macrophages, which are responsible for tissue repair. These macrophages play an important role in the immune response $[12,13]$. THP-1, a human acute monocytic leukemia cell line, has been widely used to investigate the function of human macrophages. THP-1 cells can differentiate into macrophage-like cells and M1/M2 macrophage-like cells [14, 15]. In a previous study using THP-1-derived macrophages, we found that propofol suppresses interleukin (IL)- 6 and IL-1 $\beta$ production without affecting M1/M2 differentiation and that $\mathrm{GABA}_{A}$ receptors could be involved in the suppression of cytokine production [16].

The expression of $\mathrm{GABA}_{A}$ receptor subunits on T cells and monocytes is altered by influenza infection. The administration of diazepam affects immune function and increases susceptibility to infection [17]. This finding indicates that changes in $\mathrm{GABA}_{A}$ receptor subunit expression can be involved in immune function and can exacerbate the immunosuppressive effect of diazepam.

Since the $G_{A B A}$ subunits that are expressed in immune cells during inflammation have not been fully investigated, we aimed to analyze the expression of $\mathrm{GABA}_{A}$ receptor subunit genes in THP-1 cells during macrophage differentiation. Furthermore, we aimed to investigate the changes induced by propofol administration in order to clarify the precise mechanism of the immunomodulatory effect of propofol.

\section{Methods}

\section{Aim}

We aimed to analyze the expression of $\mathrm{GABA}_{A}$ receptor subunit genes in THP-1 cells during macrophage differentiation in vitro. Furthermore, we aimed to investigate the changes induced by propofol administration in order to clarify the precise mechanism of the immunomodulatory effect of propofol.

\section{Materials}

Roswell Park Memorial Institute (RPMI) 1640 medium, dimethyl sulfoxide (DMSO), lipopolysaccharide (LPS) from Escherichia coli strain 0111:B4, and phorbol-12-myristate-13-acetate (PMA) were obtained 
from Sigma-Aldrich (St. Louis, MO, USA). Interferon (IFN)-y was obtained from R\&D Systems (Minneapolis, MN, USA). Propofol was obtained from Wako Pure Chemical Industries (Osaka, Japan).

\section{Cell culture and differentiation}

THP-1 cells (ATCC; Manassas, VA, USA) resemble primary monocytes and macrophages in morphology and differentiation properties. When exposed to PMA, THP-1 cells adhere to culture plates and start differentiating into a macrophage-like phenotype; these cells are generally used to study human macrophage functions [14]. THP-1 cells were differentiated into macrophage-like cells (M0 THP-1) through incubation for 3 days with 200 nM PMA in RPMI 1640 supplemented with $5 \%$ fetal bovine serum (FBS), penicillin (100 IU/ml), and streptomycin $(100 \mu \mathrm{g} / \mathrm{ml})$ [14]. M0 THP-1 cells were polarized into M1 macrophage-like cells (M1 THP-1) via incubation with $100 \mathrm{ng} / \mathrm{ml}$ of LPS and $20 \mathrm{ng} / \mathrm{ml}$ of IFN-ץ [15].

To evaluate the effects of propofol on $\mathrm{GABA}_{A}$ subunit gene expression during $\mathrm{M} 1$ differentiation, $\mathrm{M} 0$ THP-1 cells were differentiated into M1 THP-1 cells in the presence of propofol (25-100 $\mu \mathrm{M})$ or in that of the solvent alone $(0.05 \% \mathrm{DMSO})$. Under these experimental conditions, propofol had little effect on the viability of polarized THP-1 cells (> $95 \%$ by trypan blue staining).

\section{Quantitative real-time reverse transcription polymerase chain reaction (qRT-PCR) assays}

Total cellular ribonucleic acid (RNA) was extracted using the RNeasy Mini Kit (Qiagen, Valencia, CA, USA) according to the manufacturer's instructions. Subsequently, complementary deoxyribonucleic acid (cDNA) was synthesized from the total RNA preparations using a high-capacity cDNA reverse transcription kit (Applied Biosystems, Foster City, CA, USA) by following the guidelines. Further, qRT-PCR was performed using PowerUp SYBR Green Master Mix (Applied Biosystems) and specific primers (Takara; Table 1) on a 7500 Fast Real-Time PCR System (Applied Biosystems, CA, USA). Target messenger $(m) R N A$ levels were normalized against housekeeping $\beta$-actin mRNA levels, and the expression level relative to that of the control was calculated using the $\Delta \Delta \mathrm{Ct}$ method. The relative mRNA expression was expressed as fold expression over the control gene expression. The expression level with the control treatment was assumed to be 1 .

Table 1

Primer sequences for quantitative real-time reverse transcription polymerase chain reaction 


\begin{tabular}{|c|c|c|}
\hline Gene & Forward primer $\left(5^{\prime} \rightarrow 3^{\prime}\right)$ & Reverse primer $\left(5^{\prime} \rightarrow 3^{\prime}\right)$ \\
\hline$\beta$-actin & TGGCACCCAGCACAATGAA & CTAAGTCATAGTCCGCCTAGAAGCA \\
\hline a1 & CAGCAAGTATGAACCACATGGAAC & ATGTGTGGAATGACTTGAACAGAGA \\
\hline a2 & TCCCAAGTTTCATTCTGGCTTAACA & ACCAGTCCATGGCAGTTGCATA \\
\hline a3 & GTCACAAGTGTCGTTCTGGCTCA & AGTCCATGGCCGTCGCATA \\
\hline a4 & GTGCAGCATGTTGGCTTGTC & TCGCATAGATACACCTTTGCATGA \\
\hline a5 & ATCTTGGATGGGCTCTTGGATG & CCGAAGCTGGTGACGTAGATG \\
\hline a6 & AGGAGTCCGTCCCAGCAAGA & GTTGACAGCTGCGAACTCGATAAG \\
\hline$\beta 1$ & TCTGCAGCCAGAGTCGCACTA & ATACTCCAGCAGAGCCAGGAACA \\
\hline$\beta 2$ & CTTTGAGTTCCCAAACCAAATGTC & TGGAACTGTCAACTTGCTTCAAATG \\
\hline$\beta 3$ & GCAGAACTGCACTCTGGAAATTGA & TCCACTCCGGTAACAGCCTTG \\
\hline ү1 & GCAGCCTTGATGGAATATGGAAC & TGGATCCAGGATGGAGACCAG \\
\hline Y2 & TCTGGCAAATCTCTGTGCTG & TCACTTGACAACACCTATGTGAGAA \\
\hline ү3 & TGGATCACCACACCCAATCAG & ATCAGCGGGCAGGAGTGTTC \\
\hline$\delta$ & GTGCATGCTGGACCTGGAGA & CGGTAGCTGGTGATGGTGAAC \\
\hline
\end{tabular}

\section{Statistical analysis}

Values are expressed as the mean \pm Standard Deviation (SD), and results were obtained from six separate experiments. Differences between two groups were analyzed by an unpaired two-tailed t-test, whereas differences among multiple groups were analyzed by a one-way analysis of variance (ANOVA), followed by Bonferroni's post hoc test. All the statistical analyses were performed using GraphPad Prism software program V. 6.00 (GraphPad Software; La Jolla, CA, USA), with $\mathrm{P}<0.05$ defined as statistically significant.

\section{Results}

\section{Increase in the gene expression of the $\alpha 1, \alpha 4, \beta 1, \beta 2, Y 1$, and $\mathrm{Y} 2 \mathrm{GABA}_{\mathrm{A}}$ receptor subunits during the differentiation into MO THP-1 cells}

$G_{A B A_{A}}$ receptor subunit gene expression was investigated during macrophage differentiation. The gene expression of the $\alpha 1, a 4, \beta 1, \beta 2, \gamma 1$, and $\gamma 2 G A B A_{A}$ receptor subunits in THP-1 cells significantly increased 


\section{Decrease in the expression of the $\alpha 1, \alpha 4, \beta 1, \beta 2, y 2$, and $\delta$ subunits and increase in the expression of the $\gamma 1$ subunit during the differentiation into M1 THP-1 cells}

We examined $\mathrm{GABA}_{\mathrm{A}}$ receptor subunit gene expression in THP-1 cells during M1 differentiation. The gene expression of $\alpha 1, \alpha 4, \beta 1, \beta 2, y 2$, and $\delta$ significantly decreased during the differentiation into M1 THP-1 cells, while that of $\mathrm{y} 1$ significantly increased (Fig. 2).

\section{Increase in the expression of the $\alpha 1, \alpha 4$, and $\beta 2$ GABA $_{A}$ receptor subunits following the administration of propofol during the differentiation into M1 THP-1 cells}

We evaluated the effect of propofol on the expression of $\mathrm{GABA}_{\mathrm{A}}$ receptor subunits during $\mathrm{M} 1$ differentiation in THP-1 cells. Propofol significantly increased the $a 1, a 4$, and $\beta 2$ gene expression, while that of $\beta 1, \gamma 1, \gamma 2$, and $\delta$ was not affected by propofol administration (Fig. 3 ).

\section{Discussion}

In this study, the gene expression of the $a 1, a 2, a 4, \beta 1, \beta 2, \gamma 1, \gamma 2$, and $\delta G A B A_{A}$ receptor subunits was detected in THP-1 cells. The gene expression of $a 1, a 4, \beta 1, \beta 2, \gamma 1$, and $\gamma 2$ increased during macrophage differentiation. The gene expression of $\alpha 1, \alpha 4, \beta 1, \beta 2, \gamma 2$, and $\delta$ decreased during $M 1$ differentiation; additionally, propofol administration increased the expression of $a 1$, $a 4$, and $\beta 2$ during M1 differentiation.

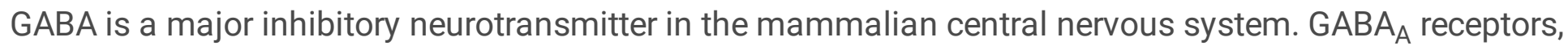
the primary target of GABA, are pentameric complexes consisting of three different subunits. Various combinations of $\mathrm{GABA}_{A}$ receptor subunits determine receptor function. Mammals express 20-30 different $\mathrm{GABA}_{A}$ receptor isoforms. The most common combination of $\mathrm{GABA}_{A}$ receptor subunits consists of two a subunits, two $\beta$ subunits, and one $y$ or $\delta$ subunit [18]. In this study, we investigated $13 \mathrm{GABA}_{A}$ receptor subunits: $a 1-6, \beta 1-3, \gamma 1-3$, and $\delta$. Most of the hypnotic effects of anesthetic agents are produced by the activation of $\mathrm{GABA}_{A}$ receptors. Classical benzodiazepines, such as diazepam, bind to two distinct binding sites on the receptor. Benzodiazepines bind to the $a-\gamma$ subunit interface present in the extracellular domain of the receptor. Benzodiazepines also bind to the $\beta$ - $\alpha$ interface and $\gamma-\beta$ interface, which are present in the transmembrane domain. Propofol binds to the $\beta-\alpha$ interface present in the transmembrane domain of the receptor [19]. 
$G_{A B A_{A}}$ receptors are present on immune cells, and $G A B A_{A}$ signaling modifies immune function. $G A B A_{A}$ receptors have been found on cluster of differentiation (CD)4+ and CD8+ T cells, macrophages, monocytes, and THP-1 cells [1-4]. The administration of diazepam in a mouse pneumonia model leads to immunosuppression, resulting in higher mortality, while the administration of the $\mathrm{GABA}_{A}$ receptor antagonist, bicuculline, counteracts the immunosuppressive effect of diazepam and decreases mortality [20]. Another study reported that benzodiazepines are involved in immunosuppressive effect, resulting in increased mortality and the incidence of pneumonia [21]. The expression of $\mathrm{GABA}_{A}$ receptor subunits on $T$ cells and monocytes is modified by influenza infection, and diazepam administration affects immune function and increases susceptibility to infection [17]. These results indicate that the expression of $\mathrm{GABA}_{\mathrm{A}}$ receptor subunits can be modified by external stimuli, such as inflammation, differentiation, and drug administration, including the administration of intravenous anesthetics.

Our previous study showed that via the effects on GABA $A_{A}$ receptors in THP-1 cells, propofol suppresses the production of inflammatory cytokines, IL- 6 and IL-1 $\beta$, during the differentiation into inflammatory M1 macrophage-like cells without affecting M1 differentiation [16]. The present study show that the gene expression of $a 1, a 4, \beta 2$, and other subunits of $\mathrm{GABA}_{A}$ receptors decreased during $\mathrm{M} 1$ differentiation, whereas addition of propofol increased the gene expression of $a 1$, $a 4$, and $\beta 2$ subunits during $M 1$ differentiation. Taken together, our previous and present data suggest that the suppression of inflammatory cytokines production during M1 differentiation in THP-1 cells by propofol administration may be associated with increasing the gene expression of $a 1, a 4$, and $\beta 2$ subunits.

$\mathrm{GABA}_{A}$ receptors have already been reported to be involved in inflammatory diseases, such as asthma, intestinal inflammation, and pulmonary fibrosis. The $\mathrm{GABA}_{A}$ receptor, $\mathrm{a} 1$, is observed in human alveolar macrophages and monocytes and is responsible for diazepam-induced immunosuppression [17, 20]. When the $\mathrm{GABA}_{A}$ receptor, $\mathrm{a} 4$, is knocked out in mice suffering from asthma, lung inflammation and airway reactivity deteriorate further [22]. In mice with stress-induced intestinal inflammation, a1, a4, and a5 $\mathrm{GABA}_{\mathrm{A}}$ receptor agonists exert anti-inflammatory effects, while a3 receptor agonists exacerbate inflammation [23]. Diazepam administration activates $\mathrm{GABA}_{A}$ a4 receptors, thereby suppressing LPSinduced lung injury and the development of pulmonary fibrosis [24]. These results suggest that $a 1$ and $a 4$ $G_{A B A}$ receptors are involved in the suppression of inflammatory responses. In addition to such previous data, our data suggest that propofol suppresses production of inflammatiory cytokines in THP-1 cells during the $M 1$ differentiation and propofol increases gene expressions of $\alpha 1, a 4$, and $\beta 2$ subunits of $\mathrm{GABA}_{A}$ receptors during M1 differenctiation. Taken together, it is quite possible that propofol exerts its immunosuppressive effect by increasing expressions of a1 and a4 subunits of GABAa receptors.

This study has several limitations. First, an artificial THP-1 cell line was used; therefore, macrophages from human peripheral blood should be examined in a clinical setting in the next study, as the results from peripheral blood can be close to those acquired in actual situations and may easily be applied in clinical therapy. Second, only gene expression was analyzed in this study; therefore, changes should be examined at the protein level to clarify the precise mechanism of immunosuppressive effect via the 
$\mathrm{GABA}_{\mathrm{A}}$ receptor. Third, we analyzed only 13 major subunits; however, all $19 \mathrm{GABA}_{\mathrm{A}}$ receptor subunits should be investigated in order to acquire more accurate results. Further studies are required to address these limitations.

\section{Conclusions}

The gene expression of $\mathrm{GABA}_{A}$ receptor subunits was modified during macrophage differentiation in THP-1 cells. In particular, the gene expression of a1 and a4 was increased by propofol administration during M1 differentiation. These results suggest that the immunomodulatory effect of propofol may be related to changes in the $\mathrm{GABA}_{A}$ receptor subunit gene expression. These results can help clinicians choose appropriate anesthetic agents for proinflammatory conditions such as highly-invasive surgery.

\section{Abbreviations}

GABA = gamma-aminobutyric acid type

$\mathrm{GABA}_{\mathrm{A}}=$ gamma-aminobutyric acid type $\mathrm{A}$

THP-1 cells = human acute monocytic leukemia cells

RPMI = Roswell Park Memorial Institute

DMSO = dimethyl sulfoxide

LPS = lipopolysaccharide

PMA = phorbol-12-myristate-13-acetate

IFN = interferon

FBS $=$ fetal bovine serum

qRT-PCR = quantitative real-time reverse transcription polymerase chain reaction

RNA = ribonucleic acid

cDNA = complementary deoxyribonucleic acid

$\mathrm{SD}=$ standard deviation

ANOVA = one-way analysis of variance

\section{Declarations}




\section{Ethics approval and consent to participate}

Not applicable.

\section{Consent for publication}

Not applicable.

\section{Availability of data and materials}

The data used to support the findings of this study are available from the corresponding author upon request. Our dataset of 13 genes does not qualify as high-throughput data, and thus, is not suitable for submission to the Gene Expression Omnibus database.

\section{Competing interests}

The authors declare that they have no competing interests.

\section{Funding}

This work was supported by a Grant-in-Aid for Young Scientists (Grant number: 19K18280) from the Ministry of Education, Culture, Sports, Science and Technology, Japan. The funding body had no role in the design of the study and collection, analysis, and interpretation of data and in writing the manuscript.

\section{Authors' contributions}

All authors contributed to the design of the experimental protocols. Material preparation, data collection, and analysis were performed by TK, AY, and MF. The first draft of the manuscript was written and edited by TK and IK, and all the authors commented on the previous versions of the manuscript. All the authors have read and approved the final version of the manuscript.

\section{Acknowledgements}

We would like to thank the Laboratory of Molecular and Biochemical Research, Research Support Center, Juntendo University Graduate School of Medicine, for technical assistance.

We would like to thank Editage (www.editage.com) for English language editing. 


\section{References}

1. Alam S, Laughton DL, Walding A, Wolstenholme AJ: Human peripheral blood mononuclear cells express GABAA receptor subunits. Mol Immunol. 2006; 43(9):1432-42.

2. Wheeler DW, Thompson AJ, Corletto F, Reckless J, Loke JC, Lapaque N, et al: Anaesthetic impairment of immune function is mediated via GABA(A) receptors. PLOS ONE 2011, 6(2):e17152.

3. Dionisio L, José De Rosa M, Bouzat C, Esandi Mdel C. An intrinsic GABAergic system in human lymphocytes. Neuropharmacology 2011; 60(2-3):513-9.

4. Mendu SK, Bhandage A, Jin Z, Birnir B. Different subtypes of GABAA receptors are expressed in human, mouse and rat T lymphocytes. PLOS ONE 2012; 7(8):e42959.

5. Bhat R, Axtell R, Mitra A, Miranda M, Lock C, Tsien RW, et al. Inhibitory role for GABA in autoimmune inflammation. Proc Natl Acad Sci U S A. 2010, 107(6):2580-2585.

6. Jin Z, Mendu SK, Birnir B: GABA is an effective immunomodulatory molecule. Amino Acids 2013; 45(1):87-94.

7. Reyes-Garcia MG, Hernández-Hernández F, Hernández-Téllez B, García-Tamayo F. GABA (A) receptor subunits RNA expression in mice peritoneal macrophages modulate their IL-6/IL-12 production. $J$ Neuroimmunol. 2007; 188(1-2):64-8.

8. Olsen RW, Sieghart W: International Union of Pharmacology. LXX. Subtypes of gamma-aminobutyric $\operatorname{acid}(\mathrm{A})$ receptors: classification on the basis of subunit composition, pharmacology, and function. Update. Pharmacol Rev. 2008; 60(3):243-60.

9. Weir CJ, Mitchell SJ, Lambert JJ. Role of GABAA receptor subtypes in the behavioural effects of intravenous general anaesthetics. Br J Anaesth. 2017; 119(suppl_1):i167-i175.

10. Zhang T, Fan Y, Liu K, Wang Y: Effects of different general anaesthetic techniques on immune responses in patients undergoing surgery for tongue cancer. Anaesth Intensive Care. 2014; 42(2):220-7.

11. Lim JA, Oh CS, Yoon TG, Lee JY, Lee SH, Yoo YB, et al. The effect of propofol and sevoflurane on cancer cell, natural killer cell, and cytotoxic $T$ lymphocyte function in patients undergoing breast cancer surgery: an in vitro analysis. BMC Cancer. 2018; 18(1):159.

12. Mosser DM, Edwards JP. Exploring the full spectrum of macrophage activation. Nat Rev Immunol. 2008; 8(12):958-69.

13. Lawrence T, Natoli G: Transcriptional regulation of macrophage polarization: enabling diversity with identity. Nat Rev Immunol. 2011; 11(11):750-61.

14. Daigneault M, Preston JA, Marriott HM, Whyte MK, Dockrell DH. The identification of markers of macrophage differentiation in PMA-stimulated THP-1 cells and monocyte-derived macrophages. PLOS ONE. 2010; 5(1):e8668.

15. Genin M, Clement F, Fattaccioli A, Raes M, Michiels C: M1 and M2 macrophages derived from THP-1 cells differentially modulate the response of cancer cells to etoposide. BMC Cancer. 2015; 15:577. 
16. Kochiyama T, Li X, Nakayama H, Kage M, Yamane Y, Takamori K, et al. Effect of propofol on the production of inflammatory cytokines by human polarized macrophages. Mediators Inflamm. 2019; 2019:1919538.

17. Sanders RD, Grover V, Goulding J, Godlee A, Gurney S, Snelgrove R, et al. Immune cell expression of GABAA receptors and the effects of diazepam on influenza infection. J Neuroimmunol. 2015; 282:97-103.

18. Olsen RW, Sieghart W. GABAA receptors: subtypes provide diversity of function and pharmacology. Neuropharmacology. 2009; 56(1):141-8.

19. Kim JJ, Gharpure A, Teng J, Zhuang Y, Howard RJ, Zhu S, et al. Shared structural mechanisms of general anaesthetics and benzodiazepines. Nature. 2020; 585(7824):303-8.

20. Sanders RD, Godlee A, Fujimori T, Goulding J, Xin G, Salek-Ardakani S, et al. Benzodiazepine augmented $y$-amino-butyric acid signaling increases mortality from pneumonia in mice. Crit Care Med. 2013; 41(7):1627-36.

21. Obiora E, Hubbard R, Sanders RD, Myles PR: The impact of benzodiazepines on occurrence of pneumonia and mortality from pneumonia: a nested case-control and survival analysis in a population-based cohort. Thorax. 2013; 68(2):163-70.

22. Yocum GT, Turner DL, Danielsson J, Barajas MB, Zhang Y, Xu D, et al. GABAA receptor a4-subunit knockout enhances lung inflammation and airway reactivity in a murine asthma model. Am J Physiol Lung Cell Mol Physiol. 2017; 313(2):L406-15.

23. Seifi M, Rodaway S, Rudolph U, Swinny JD: GABA(A) receptor subtypes regulate stress-induced colon inflammation in mice. Gastroenterology. 2018; 155(3):852-864.e853.

24. Li Y, Song D, Bo F, Deng M, Tang X: Diazepam inhibited lipopolysaccharide (LPS)-induced pyroptotic cell death and alleviated pulmonary fibrosis in mice by specifically activating GABAA receptor a4subunit. Biomed Pharmacother. 2019; 118:109239.

\section{Figures}




\section{Fig. 1}
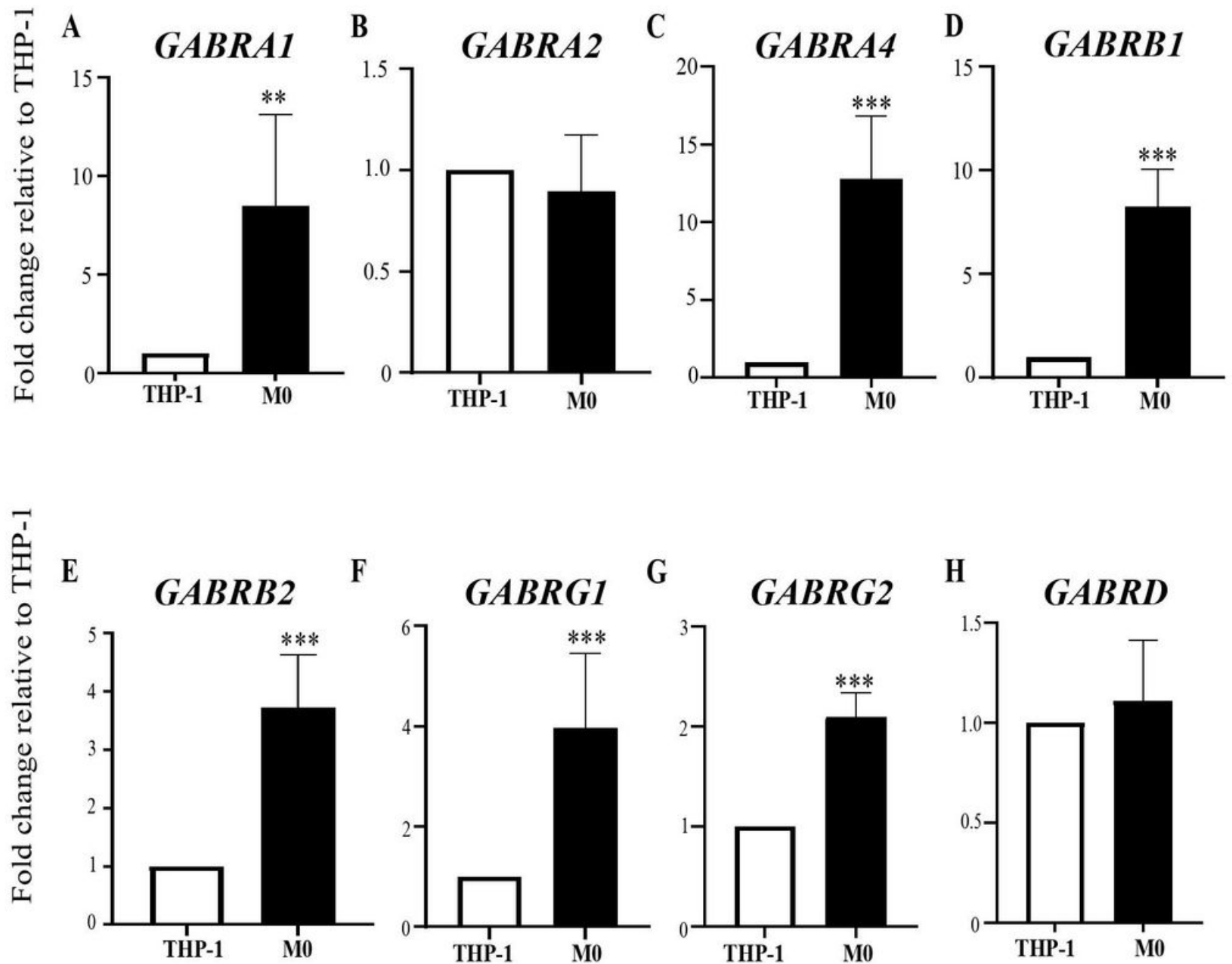

\section{Figure 1}

Changes in GABAA receptor subunit gene expression during differentiation of THP-1 cells into M0-THP-1 cells. THP- 1 cells were differentiated into M0-THP-1 cells. (A-H) RT-PCR assays of GABAA subunit mRNA levels in THP-1 cells. The gene expression of the $\alpha 1, a 4, \beta 1, \beta 2, \gamma 1$, and $\gamma 2$ GABAA receptor subunits was increased during differentiation into M0 THP-1 cells. Data were normalized relative to $\beta$-actin mRNA (internal control) and presented as mean $\pm S D\left(n=6\right.$ per group). ${ }^{*} P<0.01, * \star \star P<0.001$ compared with control cells by an unpaired t-test. Abbreviations: GABAA, gamma-aminobutyric acid type A; THP-1, human acute monocytic leukemia cell line; M0-THP-1, macrophage-like cells; RT-PCR, real-time reverse transcription polymerase chain reaction; $\mathrm{mRNA}$, messenger ribonucleic acid; SD, standard deviation 


\section{Fig. 2}
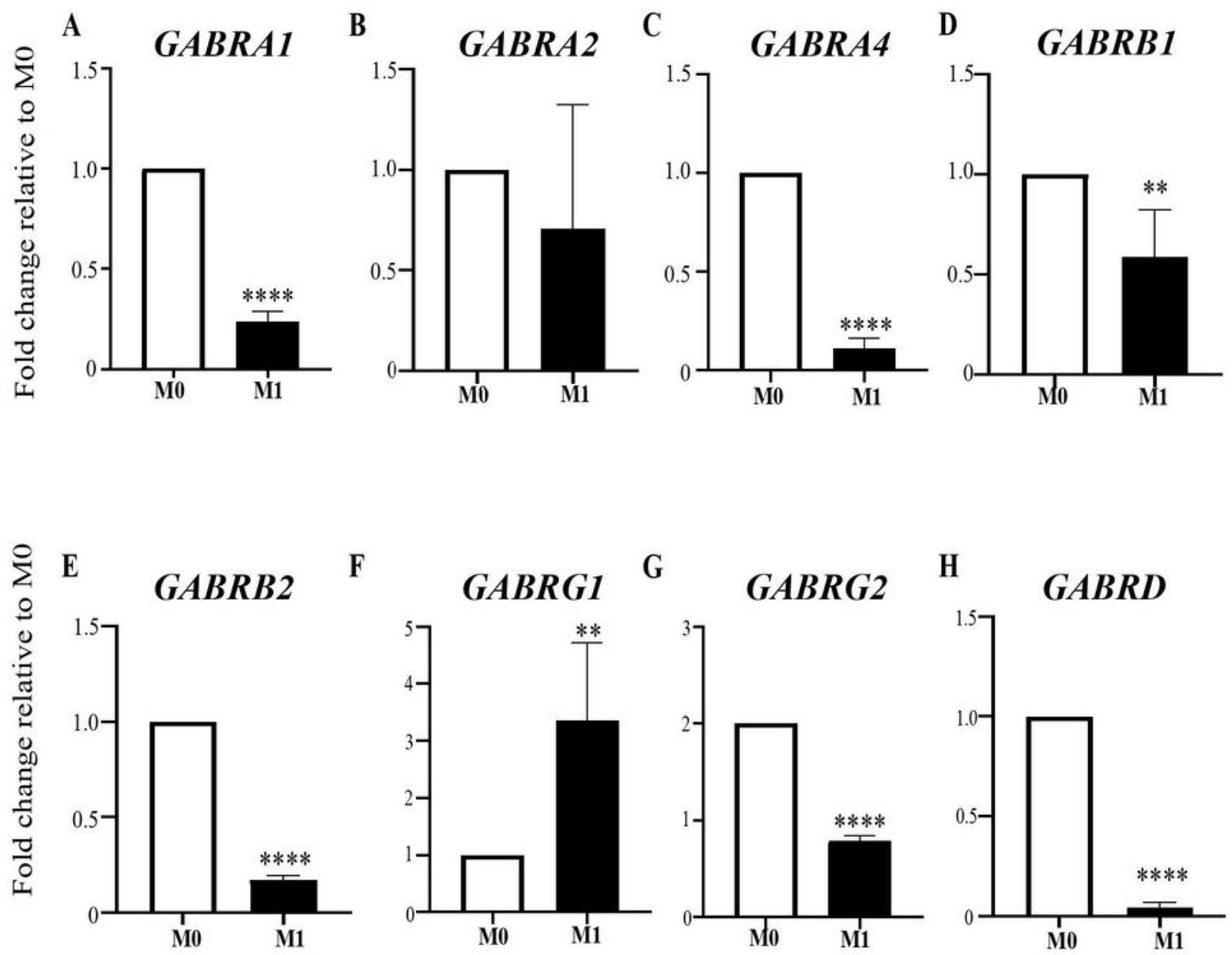

Figure 2

Changes in GABAA receptor subunit gene expression during differentiation of M0-THP-1 cells into M1THP-1 cells. M0-THP-1 cells were differentiated into M1-THP-1 cells. (A-H) RT-PCR assays of GABAA subunit mRNA levels in THP-1 cells. The expression of the $\alpha 1, \alpha 4, \beta 1, \beta 2, \gamma 1$, and $\gamma 2$ GABAA receptor subunits was decreased during differentiation into MO THP-1 cells. Data were normalized relative to $\beta$ actin $\mathrm{mRNA}$ (internal control) and presented as mean $\pm S D\left(n=6\right.$ per group). ${ }^{\star \star} \mathrm{P}<0.01,{ }^{\star \star \star \star \star} \mathrm{P}<0.0001$ compared with control cells by an unpaired t-test. Abbreviations: GABAA, gamma-aminobutyric acid type A; THP-1, human acute monocytic leukemia cell line; M0-THP-1, macrophage-like cells; M1-THP-1, M1 macrophage-like cells; RT-PCR, real-time reverse transcription polymerase chain reaction; mRNA, messenger ribonucleic acid; SD, standard deviation 
Fig. 3
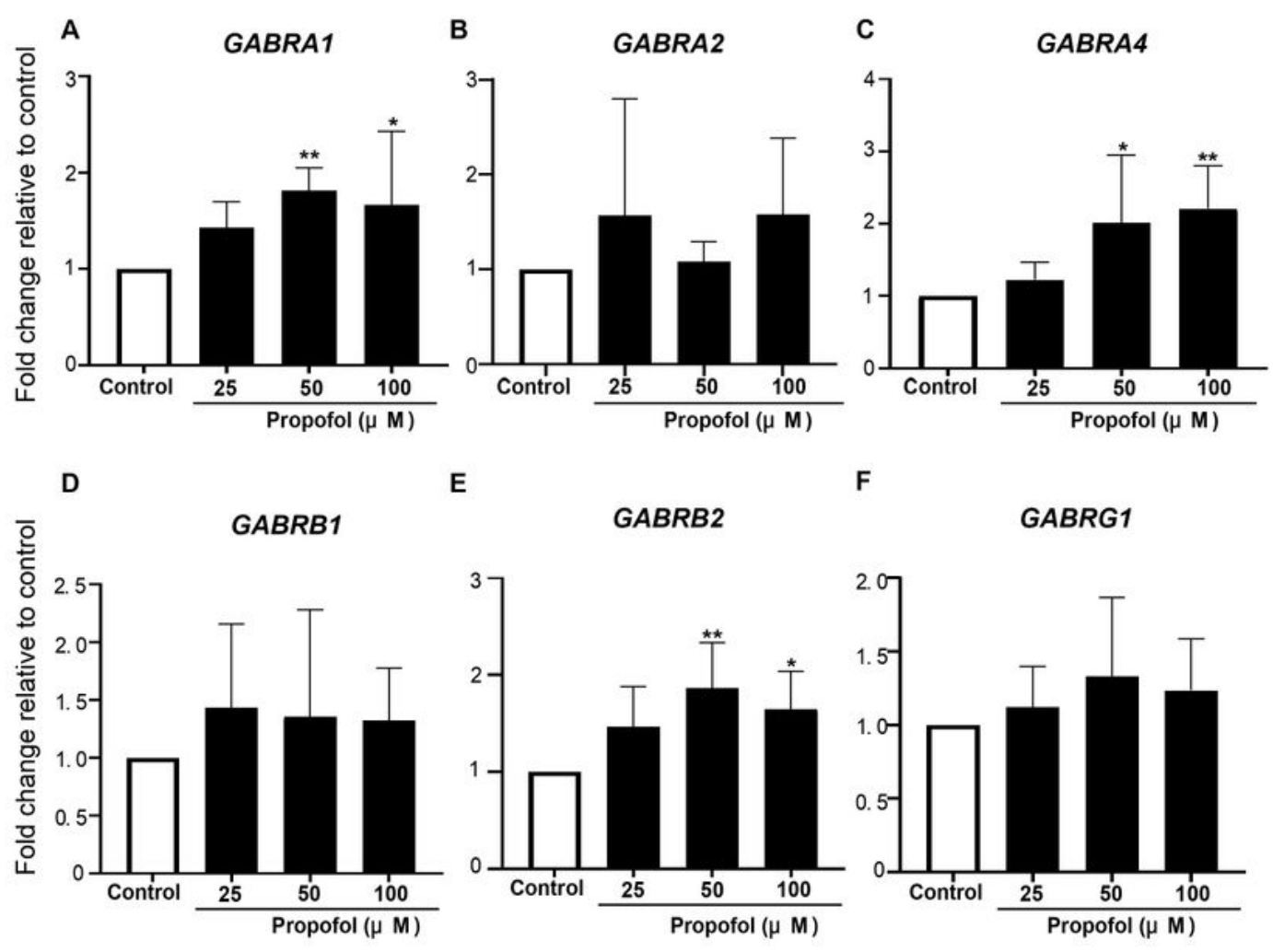

E

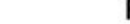

$\mathbf{F}$
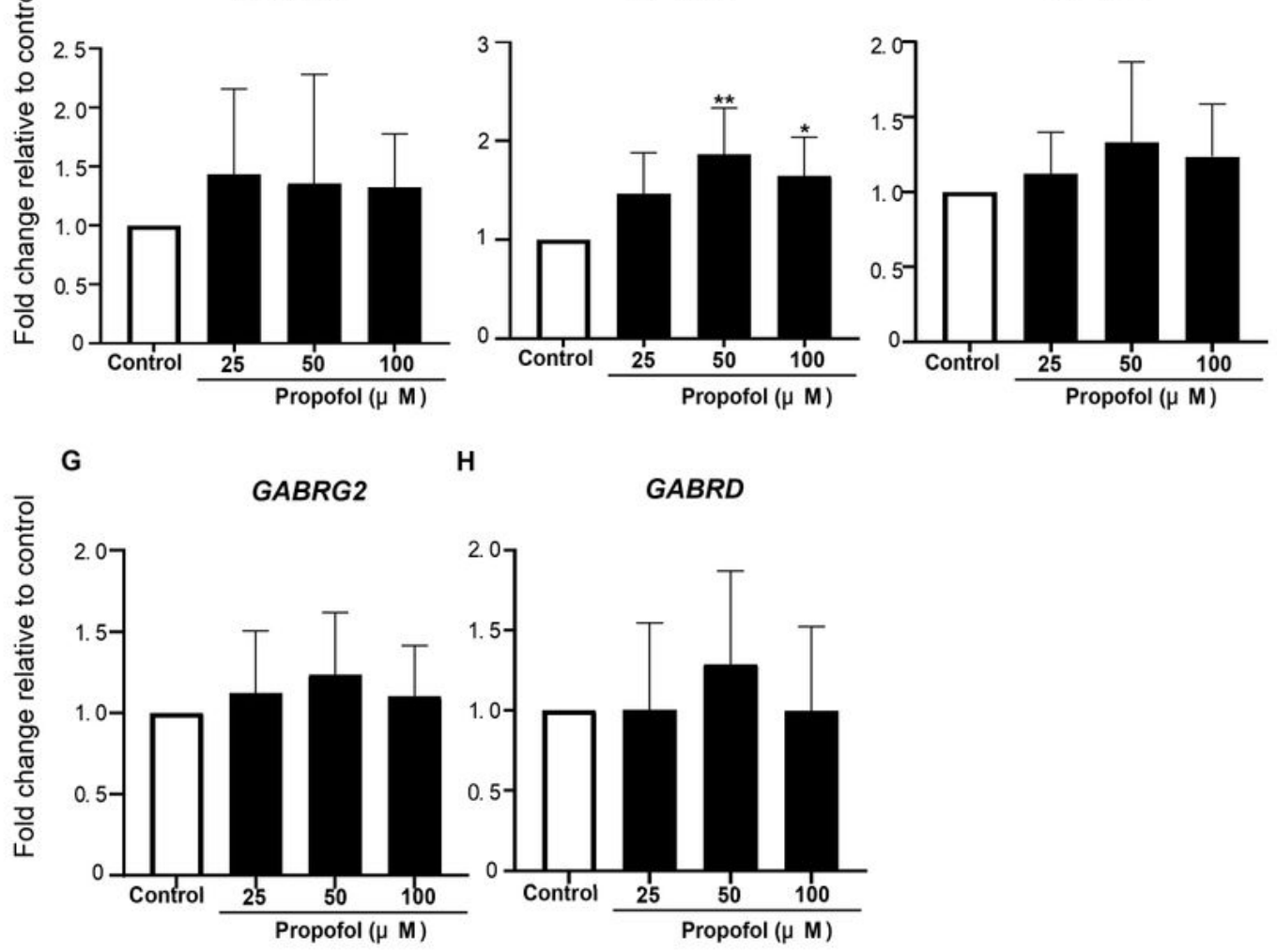

H

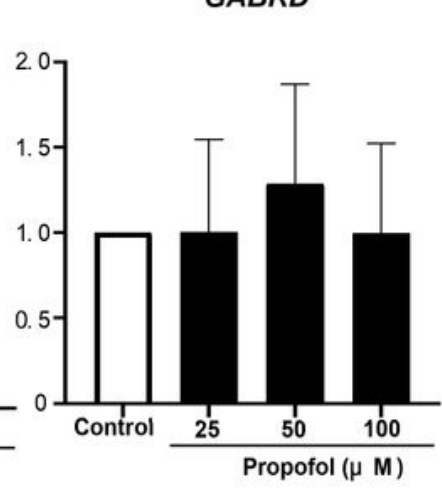

\section{Figure 3}

Changes in GABAA receptor subunit gene expression following the administration of propofol during M1 differentiation. M0-THP-1 cells were differentiated into M1-THP- 1 cells in the presence of $0.05 \%$ DMSO as the control solvent or in the presence of propofol $(25-100 \mu \mathrm{M})$. (A-H) RT-PCR assays of GABAA subunit mRNA levels in THP-1 cells. The administration of propofol $(50,100 \mu \mathrm{M})$ during differentiation into M1 THP-1 cells increased the gene expression of the $\alpha 1, a 4$, and $\beta 2$ GABAA receptor subunits. Data were 
normalized relative to $\beta$-actin mRNA (internal control) and presented as mean $\pm S D$ ( $n=6$ per group). *P< 0.05 , ${ }^{\star} \mathrm{P}<0.01$, compared with control cells by a one-way ANOVA and Bonferroni's post hoc test. Abbreviations: GABAA, gamma-aminobutyric acid type A; THP-1, human acute monocytic leukemia cell line; M0-THP-1, macrophage-like cells; M1-THP-1, M1 macrophage-like cells; DMSO, dimethyl sulfoxide; RT-PCR, real-time reverse transcription polymerase chain reaction; mRNA, messenger ribonucleic acid; SD, standard deviation; ANOVA, analysis of variance 